\title{
ACESSO À JUSTIÇA E A DEFENSORIA PÚBLICA NA AMÉRICA LATINA: DEMOCRATIZAÇÃO DE DIREITOS COMO DESENVOLVIMENTO
}

\author{
ACCESS TO JUSTICE AND THE PUBLIC DEFENDER'S OFFICE IN LATIN \\ AMERICA: DEMOCRATIZATION OF RIGHTS AS DEVELOPMENT
}

\author{
Marcia Carla Pereira Ribeiro* \\ José Alberto Oliveira de Paula Machado ${ }^{* *}$
}

\begin{abstract}
RESUMO:Oartigo tem como objetivo apresentar um breve estudo de Direito Comparado sobre a dimensão do acesso à justiça assegurada pelos diferentes modelos de Defensoria Pública nos principais países da América Latina. Foi empregado o método dedutivo de abordagem com auxílio de uma pesquisa descritiva e bibliográfica na qual se comparou o alcance desses modelos de assistência jurídica. Ao final conclui-se que, em regra, as Defensorias Públicas nos países latinos ainda não exploram sua potencialidade como instrumento de desenvolvimento.
\end{abstract}

Palavras-chave: Acesso à justiça. Defensoria Pública. Direito Comparado. Desenvolvimento.

ABSTRACT:The article aims to present a brief study of Comparative Law on the dimension of access to justice ensured by the different models of Public Defender in the main countries of Latin America. The deductive method of approach was used with the aid of descriptive and bibliographical research in which the scope of these models of legal assistance was compared. Finally, it is concluded that, as a rule, Public Defender's Offices in Latin countries have not yet exploited their potential as a development tool.

Keywords: Access to justice. Public Defender's Office. Comparative Law. Development.

Recebido: 15.05.2017

Aprovado: 25.06.2017

\section{INTRODUÇÃO}

Aprioristicamente, importa apresentar as razões, ainda que breves, da proposta do presente artigo de comparar modelos de assistência jurídica gratuita. E, para tanto, o Direito Comparado é imprescindível ao método de comparação entre institutos jurídicos afins em ordens jurídicas diferentes.

\footnotetext{
*Mestre e doutora pela Universidade Federal do Paraná (UFPR). Professora titular da Pontifícia Universidade Católica do Paraná (PUC/PR), professora associada da Universidade Federal do Paraná (UFPR). Professora do Programa de Pós-Graduação em Direito da UFPR e PUCPR. Artigo realizado no âmbito do Projeto aprovado na Chamada Públican 24/2012: Programa Universal / Pesquisa Básica e Aplicada da Fundação Araucária de Apoio ao Desenvolvimento Científico e Tecnológico do Estado do Paraná. E-mail: marcia.ribeiro@pucpr.br.

${ }^{* *}$ Mestrando em Direito Econômico e Desenvolvimento, pelo programa de Mestrado Interinstitucional da Pontifícia Universidade Católica do Paraná PUC/PR. Defensor Público do Estado de Rondônia. E-mail: zezaoopm@gmail.com.
} 
$\mathrm{O}$ acesso à justiça deve ser tomado como valor inerente ao Estado Democrático de Direito, por se tratar de um direito humano essencial para a garantia de efetividade de toda e qualquer norma e, como política pública, para o desenvolvimento do Estado e para a emancipação do homem.

O estudo realiza uma análise comparativa de sistemáticas diversas de assistência jurídica gratuita atribuídas às Defensoria Públicas na América Latina como instrumento de acesso à justiça para a população economicamente vulnerável.

$\mathrm{O}$ estudo inicia-se com a averiguação normativa do acesso à justiça como modalidade dos direitos humanos nos tratados internacionais, retomando, outrossim, a temática consagrada na publicação da obra de Mauro Cappelletti e Bryant Garth, na década de 70, denominada Acesso à Justiça.

Logo em seguida, foca-se na importante correlação desse tema com o desenvolvimento, sob o prisma da obra de Amartya Sen. Tomando-se como referência o conceito substancial de liberdade, verifica-se que o acesso à justiça é um instrumento para a promoção da capacidade geral dos indivíduos e a criação de novas oportunidades individuais e coletivas. E, é nessa perspectiva das capacidades, Capability Approach, e não de critérios meramente econômicos, que se constrói a noção seniana de desenvolvimento, como estruturação de avaliação do bem-estar individual e da liberdade para que o bem-estar seja alcançado.

Nesse aspecto, exsurge o papel fundamental da discussão sobre os modelos jurídicos que asseguram o acesso à justiça gratuita, a fim de se avalizar que esse instrumental de criação de capacidades esteja à disposição de todos e não somente de privilegiados economicamente. O próprio conceito de desenvolvimento abarca a premissa de que a liberdade substancial deve ser construída para todos de forma indistinta.

Uma das apostas políticas dos países sul-americanos foi a adoção da Defensoria Pública, modelo salaried staff, como órgão do Estado a quem é conferida essa precípua atribuição de distribuir acesso à justiça para os necessitados.

$\mathrm{O}$ artigo investiga, por método de comparação, qual dessas apostas e construções institucionais melhor atende o direito humano de acesso à justiça e melhor incrementa uma armação para a evolução da democracia e da liberdade substancial.

O método empregado é o dedutivo de abordagem que permite partir de premissas gerais para se chegar a uma conclusão específica sobre os modelos aqui confrontados. Servese, ademais, do método dialético, com o objetivo de buscar possíveis sínteses para as divergências levantadas. Quanto ao procedimento, utiliza os métodos histórico, comparativo e 
sociológico, fazendo uso da interpretação sistemática. O tipo de pesquisa é o bibliográfico, a partir de livros e artigos científicos.

\section{ACESSO À JUSTIÇA COMO DIREITO HUMANO}

A história do acesso à justiça na modernidade se confunde com a evolução do Estado, que já foi detido na mão de uma única pessoano Estado absoluto e que passou a um processo de reconhecimentos de direitos individuais e coletivos, até a consagração dos valores democráticos, especialmente o da cidadania (ALVES, 2006, p.76).

Isso porque o acesso à justiça é condição fundamental para o exercício da cidadania. Essa condição fundamental de ser cidadão, significa não só o pertencer a uma dada comunidade política, mas vai além: é, primeiro, um sinal de reconhecimento da humanidade em qualquer um (PIOVESAN, 2012, p.41).

Como expressão de todo e qualquer Estado Democrático, o direito ao acesso à Justiça é o reconhecimento da dignidade humana do indivíduo, na medida em que é o pressuposto basilar para a tutela de todos os demais direitos.

Hannah Arendt (1989, p.332) aclara que o "direito fundamental de cada indivíduo, antes de qualquer dos direitos enumerados em declarações, é o direito a ter direitos, isto é, o direito de pertencer a uma comunidade disposta e capaz de garantir-lhe qualquer direito".

Produto do movimento histórico dessa luta pela cidadania, o acesso à justiça tornou-se um direito humano fundamental, reconhecido em diversos tratados internacionais.

A Declaração Americana dos Direitos e Deveres do Homem de 1948 prevê no art. $18^{\circ}$ :

Toda pessoa pode recorrer aos tribunais para fazer respeitar os seus direitos. Deve poder contar, outrossim, com processo simples e breve, mediante o qual a justiça a proteja contra atos de autoridade que violem, em seu prejuízo, quaisquer dos direitos fundamentais consagrados constitucionalmente (DECLARAÇÃO AMERICANA DOS DIREITOS E DEVERES DO HOMEM, 1948).

Igualmente prescreve o $\operatorname{art} .8^{\circ}$ da Declaração Universal dos Direitos Humanos de dezembro do mesmo ano:

Todo ser humano tem direito a receber dos tribunais nacionais competentes remédio efetivo para os atos que violem os direitos fundamentais que lhe sejam reconhecidos pela constituição ou pela lei (DECLARAÇÃO UNIVERSAL DOS DIREITOS HUMANOS, 1948). 
Esse compromisso dos Estados com o respeito aos direitos fundamentais, foiratificado pelo Pacto Internacional de Direitos Civis e Políticos de 1966, com dispositivo consolidando esse compromisso assumido pelos Estados:

\begin{abstract}
Art. ${ }^{\circ}$. 3. Cada Estado Parte no presente Pacto compromete-se a :a.Garantir que todas as pessoas cujos direitos e liberdades reconhecidos no presente Pacto forem violados disponham de recurso eficaz, mesmo no caso de a violação ter sido cometida por pessoas agindo no exercício das suas funções oficiais; b.Garantir que a competente autoridade judiciária, administrativa ou legislativa, ou qualquer outra autoridade competente, segundo a legislação do Estado, estatua sobre os direitos da pessoa que forma o recurso, e desenvolver as possibilidades de recurso jurisdicional (PACTO INTERNACIONAL DE DIREITOS CIVIS E POLÍTICOS, 1966).
\end{abstract}

Não diferente foi o compromisso assumido pelos Estados no âmbito interamericano. Estabelece a Convenção Americana de Direitos Humanos, também conhecida como Pacto de San Jose de 1969, em seu art. $8^{\circ}$, que trata das garantias judiciais:

Toda pessoa terá o direito de ser ouvida, com as devidas garantias e dentro de um prazo razoável, por um juiz ou Tribunal competente, independente e imparcial, estabelecido anteriormente por lei, na apuração de qualquer acusação penal formulada contra ela, ou na determinação de seus direitos e obrigações de caráter civil, trabalhista, fiscal ou de qualquer outra natureza (CONVENÇÃO AMERICANA DE DIREITOS HUMANOS, 1969).

Esses compromissos atestam a ação das sociedades contemporâneas na tentativa de assegurar a relação existente entre justiça e cidadania, promovendo a liberdade e a igualdade perante a lei e na lei, já que toda e qualquer pessoa passaria a ter acesso aos Tribunais na busca de seus direitos.

Não bastaria a mera formalização de um direito em um ordenamento, seria necessário garantir também os meios de os assegurar. Um sistema jurídico e igualitário que pretenda garantir e não apenas formalizar os direitos de todos.

A iniciativa tem papel de destaque na obra de Mauro Cappelletti e Bryant Garth, na década de 70, denominada Acesso à Justiça, domada como marco doutrinário para a discussão da efetividade desse direito a reclamar direitos(CAPPELLETTI; GARTH, 1998).Assentam os autores que não basta simplesmente franquear o ingresso do indivíduo nas edificações que sediam a Jurisdição, mas sim conceder-lhe a consciência de seus direitos, mediante completa orientação jurídica que lhe possibilite até mesmo decidir entre utilizar ou não os instrumentos processuais que a legislação coloca à sua disposição. É a busca por tornar o sistema jurisdicional acessível à população, sobretudo de baixa renda, propiciando a resolução de seus 
litígios sob os auspícios do Estado e buscando resultados justos (CAPPELLETTI; GARTH, 1998, p.10).

O despertar para a efetividade desse acesso à Justiça e a busca por solução de seus problemas práticos fez surgir três enfoques.

No primeiro momento, denominado por Cappelletti e Garth $(1998$, p.12) de "primeira onda do acesso à justiça", fez-se necessário lutar pela assistência judiciária gratuita. Tal proposição se fundamenta no custo envolvido para a proposição de uma ação judicial (taxas, honorários de perícia, pagamento de advogado), o que representa uma barreia aos necessitados na procura de efetivação de seus direitos, quer por ausência de condições iniciais de arcar com essa demanda, quer pela eventual desproporcionalidade entre o benefício auferido e as custas demandadas.

A "segunda onda de acesso à justiça", identificada por Cappelletti e Garth (1998, p.18) foi a da proteção dos interesses metaindividuais, pela tutela dos direitos coletivos e difusos. Nessa linha, adotou-se instrumentos para garantir a defesa do meio-ambiente, dos consumidores, do patrimônio cultural, histórico e artístico, moralidade administrativa, entre outros.

Por fim, "a terceira onda de acesso à justiça" foi denominada pelos autores de um novo enfoque de acesso à justiça, cuja atenção está centrada no "conjunto geral de instituições e mecanismos, pessoas e procedimentos utilizados para processar e mesmo prevenir disputas nas sociedades modernas" (CAPPELLETTI; GARTH, 1998, p.25).

$\mathrm{O}$ presente artigo cinge sua abordagem à "primeira onda do acesso à justiça", notadamente na solução confiada à Defensoria Pública, modelosalaried staff, de acedência pelos diferentes países da América Latina para contemplar alguma dimensão do acesso à justiça gratuita.

Contudo, antes de avançar no destaque, imperioso é alinhavar algumas proposições sobre a simbiose entre o direito de acesso à justiça e o desenvolvimento na especificidade socioeconômica dos países sul-americanos sob a ótica do pensamento de Amartya Sen.

\section{ACESSO À JUSTIÇA E A DEMOCRATIZAÇÃO DOS DIREITOS COMO DESENVOLVIMENTO: UMA INTERLOCUÇÃO COM O PENSAMENTO DE AMARTYA SEN}

Assim como o acesso à justiça, não se pode desconsiderar que o desenvolvimento também é um direito humano. E a ideia do direito ao desenvolvimento teve sua 
alavancagemcom a instalação das Nações Unidas, sobretudo por meio da Declaração sobre o Direito ao Desenvolvimento de 1986, em que as Nações Unidas firmaram no primeiro artigo que o direito ao desenvolvimento é um direito humano inalienável em virtude do qual toda pessoa humana e todos os povos estão habilitados a participar do desenvolvimento econômico, social, cultural e político (DELGADO, 2001, p. 83).

Sobrevém que o direito ao acesso à justiça é instrumento precípuo de garantia dos demais direitos, principalmente do direito ao desenvolvimento. Não se pode denominar uma sociedade como desenvolvida se ela não garante o pleno acesso à justiça para seus cidadãos de forma indistinta.

Isso porque o acesso à justiça tem como consequência o aumento da liberdade substantiva, tema esse consagrado por Amartya Sem em sua obra "Desenvolvimento como Liberdade" (SEN, 2000). Ampliar o acesso à justiça, significa assegurar avanços na qualidade de vida da população, mesmo que isso não reflita, necessariamente, em um aumento do PIB ou da renda per capita desses sujeitos.

Por exemplo, serão beneficiados de forma direta, por meio do acesso à justiça, a busca de direitos trabalhistas, direitos dos consumidores, direitos de família, direito agrário e outras soluções de conflitos do dia-a-dia, como o direito de vizinhança. O benefício é, em última análise, ampliar a capacidade do indivíduo de construir seu próprio bem-estar. Faz-se digno citar o pensamento deAmartya Sen, Nobel de economia em 1998:

\footnotetext{
Mesmo que os mais utilizados critérios econômicos do progresso, refletidos em uma massa de estatísticas disponíveis, tendam a se concentrar especificamente no melhoramento de objetos inanimados de conveniência (por exemplo, no produto nacional bruto, PNB, e o produto interno bruto, PIB, que têm sido o foco de uma miríade de estudos econômicos do progresso), essa concentração poderia ser justificada - tanto quanto isso fosse possível — em última instância apenas através do que esses objetos produzem nas vidas humanas que eles podem direta ou indiretamente influenciar. Há um reconhecimento crescente favorável à utilização direta de indicadores da qualidade de vida, do bem-estar e das liberdades que as vidas humanas podem trazer consigo (2000, p. 86).
}

Observe-se que o autor apresenta uma abordagem distinta para o tema do desenvolvimento, relativamente ao pensamento mais usual. Isso ocorre, em grande medida, porque não se utiliza dos tradicionais indicadores de riqueza, como o PIB ou renda per capita, e sim, entende o desenvolvimento como um processo de ampliação das liberdades reais que as pessoas gozam.

Nesse ponto advém a noção de liberdade substantiva, que parte da prognose de os indivíduos serem capazes de atuar na conformação das forças socioeconômicas, a partir 
também de liberdades políticas, para reconhecer e garantir seus potencias (SEN, 2000, p. 137). Esse termo está associado ao conceito de cidadania. Assim, o sucesso de uma sociedade é avaliado, nesta visão, primordialmente pelas liberdades substantivas que os membros dessa sociedade detêm.

Se o objetivo do desenvolvimento se torna a liberdade consciente de tomada de decisão, justiça, cidadania e desenvolvimento passam, inclusive, a se confundir, pois desenvolvimento só ocorre se a sociedade estiver também assegurando a busca de justiça pela prática da cidadania. Ou melhor, o acesso à justiça e a democratização dos direitos tornam-se premissas básicas para o exercício da cidadania e o incremento do desenvolvimento

Anota-se que o desenvolvimento como liberdadepode ser interpretado como o desenvolvimento como expansão de capacitações, entendida a capacidade como a liberdade substantiva de fazer escolhas conscientes de estilos de vida (SEN, 2000, p. 140). É nesse ponto que as normas de proteção aos direitos humanos, especialmente o acesso à Justiça granjeia relevo como norte ideológico-político-jurídico de modificação de comportamentos.

Sob essa perspectiva, a problemática da desigualdade social ganha outro approach e fica mais evidente, quando transforma o foco da disparidade de renda para a disparidade na distribuição de liberdades e capacidades (SEN, 2000, p. 144). O tema do subdesenvolvimento passa a estar associado as (im)possibilidades de obtenção de renda e de sua conversão em capacidades e em qualidade de vida satisfatória para os indivíduos.

Quando o foco é a América Latina, esse debate torna-se mais delicado e desafiador pelo acentuado déficit social dessa região.

Portanto, as modificações estruturais que exercitam as potencialidades da cidadania são fundamentais para a superação do subdesenvolvimento. E o acesso à justiça parece ser o meio mais hábil para essa transformação social, já que é um instrumento à disposição do cidadão para sua emancipação e construção da sua própria liberdade pelos direitos, tanto na esfera privada quanto na esfera pública.

Porém, não seria suficiente a previsão abstrata de um número indeterminado de direitos sem que, concretamente, seja possível acessar e utilizar tais direitos. Por isso, o ponto nodal da efetividade desse acesso à justiça é a igualdade e a democratização de acesso, ou melhor, reporta-se à temática da primeira onda do acesso à justiça, dita alhures, qual seja, a luta por um modelo de assistência jurídica gratuita aos necessitados.

A ideia agora desenvolvida fica bastante clara em Amartya Sen, para quem "às vezes a ausência de liberdades substantivas relaciona-se diretamente com a pobreza econômica"(2000, p. 17). Artur Alves Pinho Vieira capta admiravelmente essa preocupação: 
As barreiras encontradas por grande parte da população, em especial a mais pobre, no que diz respeito à efetivação de seus direitos, seja pela via judicial ou administrativa, são, sem dúvidas, um grande entrave ao processo de busca da liberdade, importando numa sensível redução do desenvolvimento, na perspectiv a de Amartya Sen(2016, p. 47).

Por essa razão, as instituições jurídicas criadas para atribuir aos cidadãosseus direitos, como a Defensoria Pública, podem ser tomadasmais como instrumentos democráticos do desenvolvimento do que resultado desse processo.

\section{PRIMEIRA ONDA E O MODELO "SALARIED STAFF": DEFENSORIA PÚBLICA}

A assistência jurídica para os necessitados é instrumento de destacada importância para que se possa alcançar a efetiva igualdade jurídica entre os homens, fundamento da democracia.

No que concerne à problemática da primeira onda, imperioso é destacar que o acesso à justiça não se confunde apenas com a acessibilidade formal aos serviços judiciários, mas, constitui direito de grande relevância que obriga o ente governamental a adotar medidas concretas que tornem efetiva a conscientização e, por conseguinte, a concretização dos direitos individuais e coletivos dos cidadãos.

Com mais argúcia esclarece Cichocki Neto:

A expressão "acesso à justiça" engloba um conteúdo de largo espectro: parte da simples compreensão do ingresso do indivíduo em juízo, perpassa por aquela que enforca o processo como instrumento para a realização dos direitos individuais, e, por fim, aquela mais ampla, relacionada a uma das funções do próprio Estado a quem compete, não apenas garantir a eficiência do ordenamento jurídico; mas, outrossim, proporcionar a realização da justiça aos cidadãos (2001, p. 41).

O Poder Judiciário é apenas um dos meios que possibilita o reconhecimento e a efetivação de direitos. $\mathrm{O}$ verdadeiro objetivo está na acessibilidade judicial e extrajudicial à uma ordem jurídica justa, alcançável a todos, notadamente, aos mais necessitados, auxiliando assim ao propósito de estabelecimento de uma igualdade formal e material para toda a população.

E, essa acessibilidade para os menos afortunados, somente é possível por intermédio da criação de uma estrutura de assistência jurídica. Diferentes modelos têm sido adotados para esse desiderato, conforme assinala Cleber Francisco Alves que há: 
1) os sistemas que funcionam com advogados autônomos, os quais atuam sem receber contraprestação pecuniária dos cofres públicos, a título pro bono, em regime assistencial-caritativo; 2) os sistemas que funcionam com advogados assalariados, que trabalham normalmente em regime de dedicação exclusiva, cuja remuneração provém direta ou indiretamente dos cofres públicos, também denominado de "Salaried Staff Model"; 3) os sistemas que funcionam com advogados autônomos, que atuam como profissionais liberais e que são remunerados na base do caso-a-caso pelos cofres públicos, também denominado de "Judicare"; e 4) os sistemas mistos ou híbridos que adotam diversas modalidades de combinações possíveis entre os modelos básicos acima mencionados (2006, p. 76).

Cada um desses modelos de assistência jurídica à população de baixa renda possui seus pontos positivos e pontos negativos, conforme uma análise de abrangência, de economia e de efetiva transformação social.

O primeiro modelo possui como entrave a quantidade de demandas existente para uma pequena parcela de voluntários e a dificuldade de fazer arranjos sistematizados e planejados para melhor garantir o acesso à ordem jurídica justa para a população carente. É um modelo para situações pontuais que precisa ainda contar com a disponibilidade de altruísmo alheio, sendo, portanto, inviável para repensar o acesso à justiça como um projeto de transformação social e direito de emancipação (ALVES, 2006, p. 91).

O segundo modelo, salariedstaff, tem como ponto positivo a possibilidade de fazer do acesso à justiça uma política pública sistematizada e abrangente de conscientização de direitos e de emancipação do cidadão de baixa renda. Logo, sua estrutura, a priori, permite alcançar mais resultados para uma efetiva transformação social do indivíduo e da coletividade, atendendo de forma mais concreta o pressuposto de liberdades substantivas, construção teórica de Amartya Sen.

Assim também manifestaCappelletti e Garth:

\begin{abstract}
As vantagens dessa sistemática (o staff model) sobre o judicare são óbvias. Ela ataca outras barreiras ao acesso individual, além dos custos, particularmente os problemas derivados da desinformação jurídica pessoal dos pobres. Ademais, ela pode apoiar os interesses difusos ou de classes das pessoas pobres. Esses escritórios, que reúnem advogados numa equipe, podem assegurar-se as vantagens dos litigantes organizacionais, adquirindo conhecimento e experiência dos problemas típicos dos pobres. Advogados particulares, encarregados apenas de atender a indivíduos, geralmente não são capazes de assegurar essas vantagens. Em suma (...) esse modelo norte-americano: 1) vai em direção aos pobres para auxiliá-los a reivindicar seus direitos e 2) cria uma categoria de advogados eficientes para atuar pelos pobres, enquanto classe (1998, p. 40).
\end{abstract}

Contudo, possui a desvantagem de representar mais um custo para owelfarestate. E, ainda, pode haver uma incongruência entre o fato de o órgão instituído para esse desiderato 
ser financiado pelo governo, ao mesmo tempo em que pode se voltar contra várias das políticas estatais(CAPPELLETTI; GARTH, 1998, p. 15).

A ideia do terceiro modelo chamado de sistema "judicare" é proporcionar aos litigantes de baixa renda a mesma representação que teriam se pudessem pagar um advogado. Porém esse método tem como característica volta-se para a defesa eminentemente individual do assistido, desconsiderando a importância do enfoque nos direitos coletivos. Além disso, não há a preocupação com a formação de uma consciência dos direitos cabíveis às pessoas. As pessoas que, em regra, mais sofrem violação de seus direitos, são também as mais prejudicadas pelo fato de sequer saber identificá-los. É um modelo que exclui os grupos de baixa renda mais vulneráveis.

Dessa incursão, depreende-se que a figura institucional da Defensoria Pública se enquadra no modelo salaried staff, o qual tem ampla adesão dos países sul-americanos, conforme será demonstrado.

É com o objetivo de construir um retrato defensorial nesse continente, que se passa a traçar breves comparações entre os principais países da América Latina. Conforme ressalta Carlos Ferreira de Almeida:

O estudo de direito comparado é uma ferramenta útil por várias razões: proporciona um melhor conhecimento do próprio sistema jurídico e de seus institutos, aprimora a interpretação das normas jurídicas, serve de referência para a construção de uma política legislativa melhor qualificada e potencializa a compreensão da cultura, dos valores e dos costumes de outros países (1998, p. 93).

Os dados são extraídos do "Diagnóstico de la Defensoría Pública en América" publicado em 2012 pela a Asociación Interamericana de Defensorías Públicas (AIDEF, 2012). Os países em estudo serão: Bolívia, Brasil, Chile, Costa Rica, El Salvador, Guatemala, Honduras, México, Panamá, República Dominicana, Uruguay e Venezuela.

\section{DEFENSORIAS PÚBLICAS NA AMÉRICA LATINA}

Nesse tópico foram destacados quatro parâmetros para análise do estado atual na oferta de serviços por parte das Defensorias Públicas nos países contemplados pela pesquisa. Os critérios para avaliar a capacidade e a amplitude de alcance dessas diferentes instituições ${ }^{1}$

\footnotetext{
${ }^{1}$ Nos países de língua espanhola a nomenclatura usualmente utilizada para designar o órgão Defensoria Pública é "defensa pública" (MELO, 2012).
} 
na garantia do acesso à justiça, serão: 1) autonomia administrativa e financeira; 2) matérias de atuação; 3) atuação em direitos coletivos; 4) cobertura no território nacional.

\subsection{Autonomia administrativa e financeira}

A autonomia administrativa e financeira está relacionada à capacidade institucional de autogestão com patrimônio próprio, isto é, a auto-organização administrativa e financeira para cumprir sua missão, permitindo à instituição vincular-se apenas ao cumprimento da Constituição e das leis e desobrigando-ade cumprir ordens ou recomendações de outros órgãos ou Poderes (BARROSO, 2009, p. 177).

Extrai-se que a autonomia administrativa e financeira configura instrumento válido e fundamental para a consecução de um projeto institucional, mormente, para a garantia da liberdade de atuação dos membros, defensores públicos, impedindo a relativização da proteção dos direitos dos assistidos por ingerências e interesses governamentais externos, o que parece inevitável nas situações de dependência financeira.

Nota-se que as Defensorias Públicas da Bolívia, Brasil, Chile, El Salvador, Guatemala, República Dominicana e Venezuela gozam da autonomia administrativa e financeira, sendo que no caso do Brasil, El Salvador e Venezuela essa autonomia é prevista nas respectivasConstituições, o que robustece essa prerrogativa (AIDEF, 2012).

Já na Costa Rica, Honduras, Panamá e Uruguai as defensorias não possuem qualquer autonomia ou personalidade jurídica própria para gerir um patrimônio (AIDEF, 2012). Inclusive, na maioria desses países, a previsão institucional está na própria lei orgânica de organização do Poder Judiciário. Nesses casos, a Defensoria Pública não passa de um órgão do próprio Poder Judiciário, o que pode arrefecer sua atuação.

No México, a Defensoria Pública também não detém qualquer autonomia (AIDEF, 2012). Porém, é um órgão setorizado na Secretaria de Governo.

O propósito axiomático de examinar a autonomia administrativa e financeira é ventilar qual desses modelos possui maior potencial para a transformação social e alcance da noção desenvolvimento pretendido.

Logicamente, nos países em que essa autonomia é garantida, a instituição possui mais competência e aptidão para atingir o desiderato do acesso à justiça, não só porque esse serviço público passa a ter certa primazia política, mas pela possibilidade de prover esses órgãos de defesa da cidadania de melhorias nos aspectos de pessoal e de estrutura, para o seu bom funcionamento, conferindo-lhes a liberdade plena de atuação e de elaboração de seus planos 
administrativos e orçamentários estratégicos, condignos e compatíveis com um projeto mais eficaz.

\subsection{Matérias de atuação}

Nesse tópico faz-se uma comparação das atribuições conferidas para as Defensorias Públicas quanto à espécie de direitos para a qual se permite ao membro da instituição atuar. Em outras palavras, trata-se de checar a amplitude de acesso à justiça gratuita garantido aos cidadãos dos diferentes países.

Países no qual o órgão defensorial cinge sua atuação a pouco ramos, apequenam os direitos humanos e cravam um patamar de desigualdade de acesso à justiça. Pois, os que possuem melhores condições econômicas terão acesso a todos os direitos previstos no ordenamento jurídico, enquanto os demais terão pouca cobertura de direitos.

Bolívia, Chile, El Salvador, República Dominicana restringem a atuação do órgão para matérias penais e afetas, como execução penal e infância e juventude. Costa Rica vai um pouco além e inclui a atuação em curatela de direito de família (AIDEF, 2012).

Guatemala e México incluem o direito indígena e agrário, sendo que o México estende a atuação também para a área civil (AIDEF, 2012).

Honduras, Panamá, República Dominicana, Uruguai e Venezuela possuem atuação em um extenso rol de direitos, com algumas ressalvas, enquanto no Brasil, por previsão constitucional, a assistência jurídica gratuita é integral, incluindo todos os ramos de atuação (AIDEF, 2012).

Em suma, quanto maior a abrangência de direitos abarcadas pela atuação da Defensoria Pública maior é a potencial observância do direito humano ao acesso à justiça e de sua implicação no fomento de diferentes dimensões da liberdade substantiva.

\subsection{Atuação em direitos coletivos}

Nesse mote a apreensão ainda é com relação à amplitude das atribuições das Defensorias Públicas, mas com especial atento à capacidade de resguardo dos direitos transindividuais, problemática cada vez mais atual no debate jurídico e já cunhadacomoterceira onda por Cappelletti e Garth(1998, p. 31).

Cediço que "os direitos transindividuais se originaram de conflitos sociais instaurados no último século, obrigando o reconhecimento e a proteção de direitos como a educação, 
segurança, meio ambiente, saúde, dentre outros de natureza fluída, cuja titularidade compete a todo cidadão" (GOMES JUNIOR, 2008, p. 4).

E o que caracteriza os direitos transindividuais não é apenas o fato de serem compartilhados por vários titulares individuais reunidos pela mesma relação fática ou jurídica, mas também pela necessidade de substituir o acesso individual à justiça por um acesso coletivo, o que permitirá a solução de conflitos com mais eficiência, evitando assim a insegurança jurídica.

As Defensorias Públicas por atuarem, a priori, na tutela individual, possuem um radar natural que as autoriza a identificar muito mais rápido o dano coletivo e o seu reparo (MACEDO SILVA, 2013). Por conseguinte, modelos de Defensoria Pública que atuam na proteção de direitos coletivos lato sensu possuem maior capacidade de transformação social, tornando mais igual e eficiente o acesso à justiça.

Nesse item, apenas o Brasil, Honduras e República Dominicana atendem a expectativa de atuação nos direitos coletivos. Nos demais países, a competência das Defensorias Públicas limita-se à tutela individual e há motivo (AIDEF, 2012).

Nos países latinos criou-se a figura do Defensor del Pueblo ${ }^{2}$ para a tutela transindividual. A DefensoríadelPueblo é uma espécie de Ouvidoria Nacional de Direitos Humanos, ou Ombudsman e não se confunde com assistência jurídica ou defensa pública. O Defensor del Pueblo não integra uma carreira e sua nomeação é política para mandatos (MELO, 2012).

\subsection{Cobertura no território nacional}

Por fim, neste tópico a preocupação reside na identificação da extensão dos serviços das Defensorias Públicas em cada unidade nacional. Refere-se ao seu estágio de implantação

\footnotetext{
2 "Esta foi, sem dúvida, uma das principais inovações em termos de acesso à justiça na América do Sul, em grande parte inspirada na Constituição espanhola de 1978. O ombudsman ou defensor delpueblo, como ficou conhecido na maior parte dos países de língua espanhola, é uma figura vinculada à defesa e à proteção dos direitos fundamentais do homem que remonta à República Romana.[...] Nos países iberoamericanos sua primeira aparição ocorre nas constituições democráticas de Portugal (1976) e Espanha (1978) e dali se expande para vários países da América Latina, como o território de Porto Rico (1977), Guatemala (1985), México (1990), El Salvador (1991), Colômbia (1991), Costa Rica (1992), Paraguai (1992), Honduras (1992), Peru (1993), Argentina (1993), Bolívia (1994), Nicarágua (1995), Equador (1996) e Panamá (1997). Atualmente, Venezuela e Uruguai desenvolvem estudos nesse sentido (MAIORANO, 1986a e 1986b). Apesar das especificidades, o funcionário que recebe as funções de ombudsman tem algumas atribuições que podem ser generalizadas: independência frente aos partidos; investidura pelo Legislativo; atribuição de ouvir queixas do público contra injustiças, abusos ou erros da administração pública estatal; poderes de investigar, criticar e dar publicidade às ações administrativas" (D'ARAÚJO, 2001, p.155).
} 
quanto à sua disposição aos cidadãos para o atendimentodo maior número de localidades possíveis.

Em regra, todos países assinalaram que há atendimento em todo o território nacional, salvo Brasil, México e República Dominicana que informam insuficiência de número de membros para a demanda (AIDEF, 2012).

Nesse aspecto, pode-se observar que a dimensão territorial e populacional de cada unidade nacional interfere no alcanceda completude de acesso à justiça, já que o Brasil e o México são os países do diagnóstico com maior população e maior área de extensão.

Quanto ao Brasil, a Emenda Constitucional no 80 de 2014 acrescentou uma previsão no art.98 do Ato das Disposições Transitórias no sentido de que no prazo de oito anos, a União, os Estados e o Distrito Federal deverão contar com defensores públicos em todas as unidades jurisdicionais, devendo a lotação seguir as regiões com maiores índices de exclusão social e adensamento populacional.

\section{CONCLUSÃO}

O direito do acesso à justiça não é apenas uma garantia constitucional, é uma prerrogativa associada aos Direitos Humanos, dotada de grande importância quando se considera o desafio de transformação das estruturas sociais e políticas construídas na modernidade.

A locução acesso à justiça tem uma difícil definição em razão da ampla abrangência de seu significado, pois compreende todos os meios a que se destina a um fim, a saber: a reivindicação dos direitos dos cidadãos, orientação jurídica, educação de direitos e a solução dos litígios dos indivíduos, por meio de um sistema que deve proporcionar não só o acesso a todos aos resultados e soluções justas, mas, principalmente, a ampliação das capacitações.

Um dos desafios do acesso à justiça pode ser resumido na denominada primeira onda,expressão cunhada por Mauro Cappelletti e BriantGarthparafazer referênciaà necessidade de criação de estruturas de assistência jurídica para a população desfavorecida, sob penade violaçãoao princípio da igualdade, assim como de se operar em descumprimentoao direito humano de acesso à justiça.

E mais do que a distinção terminológica, o imperioso é que a assistência jurídica se torne efetiva e desempenhe a nobre função de humanizar o acesso à ordem jurídica, deixando o diminuto papel de mera assistência judiciária. Não se trata, aqui, da garantia meramente formal do direito de ação, mas sim, do acesso efetivo e pleno à Justiça, à ordem jurídica, da 
possibilidade do ser humano conviver em uma sociedade onde o direito é instrumento de exercício e acréscimo da liberdade substantiva. Em outras palavras, assistência jurídica entende-se como acesso à justiça em sua plenitude e não acesso ao Judiciário.

É por meio das Defensorias Públicas, salaried staff model, que a América Latina tem cumprindo sua política pública de garantir o acesso à Justiça das pessoas desprovidas de recursos financeiros para fazer frente às despesas com advogado e custas do processo. A criação de mecanismos para permitir que qualquer pessoa possa pleitear seus direitos, independentemente de seus recursos materiais, é um dos mais importantes e fundamentais instrumentos de afirmação dos direitos humanos e, consectariamente, do desenvolvimento no Estado Democrático de Direito.

A ideia de acesso à justiça inclusivo coaduna com a proposta de desenvolvimento de Amartya Sen na qual se vislumbra a ampliação das capacidades pessoais como o fim do processo de desenvolvimento, ao revés das abordagens tradicionais que avaliam e medem este processo com base nos meios ou instrumentos do desenvolvimento - a renda, a riqueza, a industrialização, a acumulação de capital. O foco da avaliação são as pessoas, consideradas sob o aspecto de suas liberdades na concepção de fim e meio para o desenvolvimento.

Para essa linha teórica, desenvolver uma comunidade, uma sociedade, um país, destarte, é ampliar a capacidade de seus membros de viverem do modo que, com razão, desejam e valorizam. Portanto, a avaliação de uma política de desenvolvimento deve procurar medir os efeitos dessa política sobre a extensão das capacidades dos indivíduos de forma democrática. E é por isso que esse deve ser o próprio propósito do acesso à justiça conferido pelas Defensorias Públicas na América Latina.

O estudo comparado teve como objetivo avaliar em que medida e alcance as Defensorias Públicas de cada país seriam capazes de atender as premissas de desenvolvimento como liberdade, a partir da amplitude garantida de acesso à justiça.

Para tanto, quatro elementos foram sopesados de cada modelo de Defensoria Pública, quais sejam: 1) autonomia administrativa e financeira; 2) matérias de atuação; 3) atuação em direitos coletivos; 4) cobertura no território nacional.

A conclusão é que os modelos encontrados, em sua grande maioria, ainda carecem de uma grande transformação para cumprir o desiderato pretendido. Observa-se que a maior parte das Defensorias Públicas não possui sequer autonomia administrativa para se auto organizarem para melhor cumprir seu papel.

Aliás, adverte-se que, segundo os dados comentados, na maior parte dos países pesquisados, esse modelo salaried staff foi uma opção mais propriamente de assistência 
jurídica para demandas criminais do que uma política pública de acesso à justiça como instrumento de ampliação de oportunidades e capacidades. Os âmbitos de atuação das defensorias tendem a um rol limitado de direitos e não prezam por uma assistência jurídica integral - pretensão adota no sistema brasileiro.

Tal fato é corroborado com a constatação que apenas no Brasil, Honduras e República Dominicana, a Defensoria Pública possui legitimidade para a cogente atuação em direitos coletivos.

E ainda, os sistemas comparados parecem, em geral, se esgotar no âmbito judicial. Os defensores públicos, como agentes de promoção da dignidade da pessoa, deveriam atuar extrajudicialmente, difundindo mecanismos alternativos de solução de controvérsias e, especialmente, participando diretamente junto às comunidades e aos movimentos sociais inclusive com a colaboração efetiva na educação e capacitação jurídica da população. Mas essa perspectiva não demonstra ser, a priori, os desígnios das Defensorias Públicas sulamericanas.

Esse diagnóstico é uma grande oportunidade de agregar dados e traçar análises dos países do continente Americano que adotam diferentes soluções para a garantia do direito de acesso à justiça. O intercâmbio de informações é essencial para se conhecer as distintas experiências e perfis desse órgão, que ainda demonstra ser muito insipiente e não conhecer seu verdadeiro potencial.

Em linhas gerais, o modelo brasileiro ainda que deficitário e sujeito a críticas, favorece mais a implementação de uma política mais diretiva às causas sociais dos conflitos e aquelas à margem de qualquer acesso ao conhecimento do direito, o que vai ao encontro do conceito mais alargado de acesso à justiça que permeia todo este estudo, o que inclui a função de orientação e educação em direitos, tornando essa capacitação uma fonte de emancipação e uma ação impulsora do desenvolvimento social.

É imperativo abalizar um modelo de assistência jurídica pleno, integrador, responsivo e inclusivo que opere com a técnica jurídica tradicional e também com ferramentas educativas e políticas que criam um novo poder democrático na mão dos mais pobres: a liberdade de construir sua própria transformação social. 


\section{REFERÊNCIAS}

AIDEF. Diagnóstico de ladefensoría pública en América. 2012. Disponível em: $<$ http://www.forumjustica.com.br/wp-content/uploads/2015/08/Diagnostico-DP.pdf > . Acesso em: 20.04.2017.

ALVES, Cleber Francisco. Justiça para todos! Assistência Jurídica gratuita nos Estados Unidos, na França e no Brasil. Rio de Janeiro, Lumen Juris, 2006.

ARENDT, Hannah. Origens do Totalitarismo - Antissemitismo, imperialismo, totalitarismo. Tradução de Roberto Raposo. São Paulo: Companhia das Letras, 1989.

BARROSO, Luiz Roberto. Curso de direito constitucional contemporâneo. São Paulo: Saraiva, 2009.

CAPPELLETTI, Mauro; GARTH, Brian. Acesso à Justiça. Tradução de Ellen Gracie Northfleet. Porto Alegre: Sérgio Antônio Fabris, 1988.

CICHOCKI NETO, José. Limitações ao acesso à justiça. Curitiba: Juruá, 2001.

CONVENÇÃO AMERICANA SOBRE DIREITOS HUMANOS. 1969. Disponível em: $<$ https://www.cidh.oas.org/basicos/portugues/c.convencao_americana.htm $>$. Acesso em: 20.04. 2017.

D'ARAUJO, Maria Celina. Democracia e novas institucionalidades jurídicas na América Latina. Revista de Administração Pública. Ano 2001. n.1. jan/fev. Disponível em: < http://bibliotecadigital.fgv.br/ojs/index.php/rap/article/download/6365/4950>. Acesso em: 29.12.2017.

DECLARAÇÃO AMERICANA DOS DIREITOS E DEVERES DOS HOMENS. 1948. Disponível em: <https:/www.cidh.oas.org/basicos/portugues/b.Declaracao_Americana.htm>. Acesso em: 20 abr. 2017.

DECLARAÇÃO SOBRE O DIREITO AO DESENVOLVIMENTO. ONU. 1986. Disponível em: $<$ http://www.direitoshumanos.usp.br/index.php/Direito-ao-Desenvolvimento/declaracaosobre-o-direito-ao-desenvolvimento.html>. Acesso em: 20.04.2017.

DECLARAÇÃO UNIVERSAL DOS DIREITOS DOS HOMENS. ONU. 1948. Disponível em: $<$ http://www.ohchr.org/EN/UDHR/Documents/UDHR_Translations/por.pdf $>$. Acesso em: 20.04.2017.

DELGADO, Ana Paula Teixeira. O direito ao desenvolvimento na perspectiva da globalização: paradoxos e desafios. Rio de Janeiro: Renovar, 2001.

FERREIRA DE ALMEIDA, Carlos. Introdução ao Direito Comparado. Coimbra: Almedina, 1998.

GOMES JUNIOR, Luiz Manoel. Curso de direito processual civil coletivo. 2. ed. São Paulo: Forense. 2008. 
MACEDO SILVA, Michelle Valéria. Direitos humanos. Acesso à justiça. Defensoria pública. Pobreza. Exclusão social. Revista da Defensoria Pública da União, ano 2013, n. 6. Disponível em: $<$ http://revistadadpu.dpu.def.br/index.php/dpu/article/view/59/63>. Acesso em: 26.04.2017.

MELO, André Luís Alves de. Assistência jurídica nos países de língua espanhola: defensa publica x defensoria delpueblo. Revista Jus Navigandi, ISSN 1518-4862, Teresina, ano 17 , n. 3114, 10 jan. 2012. Disponível em: <https://jus.com.br/artigos/20828>. Acesso em: 01.05.2017.

PACTO INTERNACIONAL DE DIREITOS CIVIS E POLÍTICOS. 1966. Disponível em: $<$ http://www.planalto.gov.br/ccivil_03/decreto/1990-1994/d0592.htm>. Acesso em: 20.04.2017.

PINHO VIEIRA, Artur Alves. Acesso à justiça: notas de um direito social sob o prisma de Amartya Sen. Revista da Defensoria Pública da União, ano 2016, n. 09. Disponível em: $<$ http://revistadadpu.dpu.def.br/index.php/dpu/issue/viewIssue/1/1 > . Acesso em: 29.12.2017.

PIOVESAN, Flávia. Direitos humanos e o direito constitucional internacional. 13. ed. São Paulo: Saraiva, 2012.

SEN, Amartya. Desenvolvimento como liberdade. São Paulo: Companhia das Letras, 2000. 